\title{
New video evidence links trunk and knee motion in non-contact ACL injury
}

\author{
Karim M Khan
}

Welcome to this almost summer issue of BJSM packed chock full with solutions. Please also make sure you checked last month's "ACL issue" as well the bumper Concussion supplement. ${ }^{2}$ Continuing the anterior cruciate ligament (ACL) themebecause who can get enough of thatAssociate Editor Hewett provides another jewel in his crown of contributions that aim to make ACL history. Last month, he and newly-minted $\mathrm{PhD}$ Carmen Quatman ${ }^{3}$ reviewed the arguments for the valgus forces being the primary mechanism in women; this contrasts with the "saggital plane" forces theory. That certainly stirred the pot!

\section{BRAND NEW ACL DATA!}

This month comes the second punch of this flurry-original data showing clearly that in women ACL injury occurred when the combination of lateral trunk and knee abduction angles were greater than those adopted by ACL-injured male athletes and uninjured female athletes. ${ }^{4}$ Before leaving the ACL issue-thanks for the e-mails about the surgical controversy-which graft to use, patellar tendon ${ }^{5}$ versus hamstring; ${ }^{6}$ and a reminder to check out BJSM's podcast on that issue and ACL rehab featuring global gurus Professors Elizabeth Arendt and Lars Engebretsen.

\section{SHOULDER EXAM AND THEME ISSUE}

For some folk, there is more to sport than the ACL. BJSM's systematic review of shoulder examination ${ }^{7}$ continues to reign at the "top of the pops" (now that is revealing my vintage-our Twitter generation won't recognise that halcyon 70 s phrase). Because of the everyday

Correspondence to: Professor K M Khan, UBC, Centre for Hip Health and Mobility, and Department of Family Practice, 303-2647 Willow St at VGH, Vancouver V5ZIM9, Canada; karim.khan@familymed.ubc.ca relevance of shoulder problems, BJSM's February 2010 issue is about the "sporting shoulder". Please ignore the Lancet and send high quality research, reviews or key editorial pieces to the BJSM online editorial office at http://submit-bjsm.bmj.com by 1 September 2009. Guest editors Babette Pluim, Robert van Cingel and Ben Kibler are particularly keen on papers that provide immediate or short-term clinical application so that clinicians can better manage patients with shoulder pain and injuries. This fits with the BJSM commitment to "innovation, education and translation".

\section{GROIN PAIN SERIES: “GLUTEAL TRIANGLE"}

Our virtual groin theme issue-groin papers spread across a series of 2008 and 2009 issues-downloads heavily each month. This month you can gain new insight into some challenging anatomythe "gluteal triangle". Read it here and if you like the approach you can also review the popular "groin triangle" paper. 9 More great papers to follow-check them online first or wait by your door for $B J S M$ to come through the mail slot.

\section{TENDINOPATHY: A NEW MANAGEMENT APPROACH}

Thanks to Jill Cook for editing the wellreceived and clinically relevant April tendinopathy issue. ${ }^{10}$ And in this current issue you can read her explanations as to why sometimes an injured tendon responds to more loading-and other times why it needs relative rest. This paper is certainly a Masterclass and I predict it will have a big impact on how clinicians will manage tendinopathy. Please check it out ${ }^{11}$ and share your thoughts and experience via the e-letters or blog.
IOC LINKS WITH BJSM FOR FOUR ADDITIONAL ISSUES PER YEAR!

I am delighted that $B J S M$ readers will gain four additional issues per year courtesy of the International Olympic Committee (IOC). There will be additional journal issues in September and December 2009 to "promote the health of the athlete". From 2010 onwards, BJSM will publish four additional journal issues per year (16 issues per year plus any supplementsgreat value for readers!). You'll hear more about this liaison in the journal and on the blog, but kudos to Professor Lars Engebretsen for making this enterprise happen and to guest editors Jon Drezner and Babette Pluim for steering the first of these theme issues-sports cardiology in September's BJSM.

\section{Competing interests: None.}

Accepted 8 May 2009

Br J Sports Med 2009:43:391.

doi:10.1136/bjsm.2009.061952

\section{REFERENCES}

1. Bahr R. ACL injuries_-problem solved? Br J Sports Med 2009:43:313.

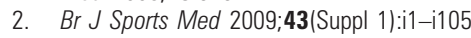

3. Quatman CE, Hewett TE. The anterior cruciate ligament injury controversy: is "valgus collapse" a sex-specific mechanism? Br J Sports Med 2009:43:328-35.

4. Hewett TE, Torg JS, Boden BP. Video analysis of trunk and knee motion during non-contact anterior cruciate ligament injury in female athletes: lateral trunk and knee abduction motion are combined components of the injury mechanism. Br J Sports Med 2009;43:417-22.

5. Carmichael JR, Cross MJ. Why bone-patella tendon-bone grafts should still be considered the gold standard for anterior cruciate ligament reconstruction. Br J Sports Med 2009;43:323-5.

6. Pinczewski L, Roe J, Salmon L. Why autologous hamstring tendon reconstruction should now be considered the gold standard for anterior cruciate ligament reconstruction in athletes. $\mathrm{Br} J$ Sports Med 2009;43:325-7.

7. Hegedus EJ, Goode A, Campbell S, et al. Physical examination tests of the shoulder: a systematic review with meta-analysis of individual tests. Br J Sports Med 2008;42:80-92.

8. Franklyn-Miller A, Falvey E, McCrory P. The gluteal triangle: a clinical patho-anatomical approach to the diagnosis of gluteal pain in athletes. $\mathrm{Br} J$ Sports Med 2009;43:460-6

9. Falvey EC, Franklyn-Miller A, McCrory PR. The groin triangle: a patho-anatomical approach to the diagnosis of chronic groin pain in athletes. $\mathrm{Br} J$ Sports Med 2009:43:213-20.

10. Cook J. In search of the tendon holy grail: predictable clinical outcomes. Br J Sports Med 2009;43:235.

11. Cook JL, Purdam CR. Is tendon pathology a continuum? A pathology model to explain the clinical presentation of load-induced tendinopathy. Br J Sports Med 2009:43:409-16. 